\title{
Perceptions, Facilitators, and Barriers to Consumption of Whole Grain Staple Foods among Overweight and Obese Tanzanian Adults: A Focus Group Study
}

\author{
Alfa J. Muhihi, ${ }^{1}$ Emanuel Shemaghembe, ${ }^{2}$ Marina A. Njelekela, ${ }^{3}$ Dorothy Gimbi, ${ }^{4}$ \\ Kissah Mwambene, ${ }^{5}$ Vasanti S. Malik, ${ }^{6}$ Nicole M. Wedick, ${ }^{6}$ Donna Spiegelman,, 8 \\ Frank B. Hu, ${ }^{6}$ and Walter C. Willett ${ }^{6,7}$ \\ ${ }^{1}$ Ifakara Health Institute, P.O. Box 53, Ifakara, Morogoro, Tanzania \\ ${ }^{2}$ Department of Sociology and Anthropology, College of Arts and Social Sciences, University of Dar es Salaam, \\ P.O. Box 35052, Dar es Salaam, Tanzania \\ ${ }^{3}$ Department of Physiology, Muhimbili University of Health and Allied Sciences, P.O. Box 65001, Dar es Salaam, Tanzania \\ ${ }^{4}$ Department of Food Science and Nutrition, Sokoine University of Agriculture, P.O. Box 3006, Morogoro, Tanzania \\ ${ }^{5}$ Department of Psychiatry and Mental Health, Muhimbili National Hospital, P.O. Box 65000, Dar es Salaam, Tanzania \\ ${ }^{6}$ Department of Nutrition, Harvard School of Public Health, Boston, MA 02115, USA \\ ${ }^{7}$ Department of Epidemiology, Harvard School of Public Health, Boston, MA 02115, USA \\ ${ }^{8}$ Department of Biostatistics, Harvard School of Public Health, Boston, MA 02115, USA \\ Correspondence should be addressed to Alfa J. Muhihi, selukundo@gmail.com
}

Received 15 September 2011; Accepted 10 October 2011

Academic Editors: A. Bramesfeld, A. H. Garde, and J. Kirigia

Copyright () 2012 Alfa J. Muhihi et al. This is an open access article distributed under the Creative Commons Attribution License, which permits unrestricted use, distribution, and reproduction in any medium, provided the original work is properly cited.

Background. Stiff porridge (ugali) made from unrefined maize flour has been a staple food in Tanzania. Recently, high intakes of refined carbohydrates and energy-dense foods have been documented in urban areas in Tanzania. We assessed cultural acceptability, perceptions and barriers to consumption of unrefined carbohydrates in Tanzania. Methods. Twelve focus group discussions (FGDs) were conducted among 44 overweight and obese adults aged 40-65 years. All FGDs were audio-recorded, and QSR N6 software was used for data analysis. Results. Most participants (77\%) had tried and liked unrefined maize ugali prior to our study. For unrefined sorghum ugali, 12 participants had tried it before, and 9 of them liked it. Brown rice was found to be unpopular and was considered a diet for diabetic patients; four participants had tried it before and all reported to like it. Sensory appeal, availability, and affordability were key facilitators whereas high cost, scarcity, and negative perceptions toward whole grains were mentioned as barriers to consumption of unrefined carbohydrates. Conclusion. Our study has identified facilitators and barriers to consumption of unrefined carbohydrates in Tanzania. Educational strategies are recommended in order to increase consumption of unrefined carbohydrates and consequently reduce diet-related chronic diseases in Tanzania.

\section{Introduction}

Tanzania is undergoing a "nutrition transition" due to changes in dietary habits, especially among middle- and highincome groups living in urban areas who tend to consume high energy dense and processed foods [1]. This nutrition transition is associated with an increase in diet-related chronic diseases such as obesity and type 2 diabetes mellitus (T2DM) $[2,3]$.
The traditional staple diet in Tanzania is based on cereals (maize and sorghum), starchy roots (cassava), and pulses (mainly beans) [4]. Cereals and root tubers serve as staples for the majority of the population in both rural and urban areas. Maize is consumed in all regions in Tanzania. However, there is a regional distribution in staple foods, including other cereals such as millet and tubers like yams and sweet potatoes. The main staple food is "ugali" which is a stiff 
porridge traditionally made from course ground or handpounded maize or sorghum or cassava flour, but is now made from refined flour [5]. Ugali is usually eaten with side dishes either made of vegetables, fish, sardines, pulses, or meat. The diet is often monotonous with limited diversity and is based on starchy foods which have lost their high fiber content due to the rampant processing of grains. Despite a wide variety of food produced in Tanzania, the dietary diversification index is very low, as starchy foods provide almost three quarters of the total energy supply [6]. The most common side dish accompanying ugali is cooked green leafy vegetables. Frequency of vegetable consumption is high, especially among the poor rural communities compared to urban and wealthy households [7]. However, the quantities are generally small with limited nutrient intake. Children have been reported to consume more indigenous fruits followed by adult women [8], but consumption is limited by seasonal variation in their availability. We have already documented the relationship between dietary patterns and cardiovascular disease risk [9], with high consumption of carbohydrate diets (more than 90\%) among urban, rural, and Masai populations.

Rapid urbanization and liberalization of free market have led to a rise in the use of imported cereals in Tanzania [10]. Access to food in urban areas is dependent on cash exchange, with few exceptions, where urban food production contributes directly to household intake. Food supplied to cities, either through national or international supply channels, determines foods available for purchase [11]. For urban dwellers, food access hinges primarily on the household's ability to purchase food. Most urban poor have neither large food stores, nor do they have access to areas for their own food production. Urban residents in Mozambique purchase $83 \%$ of the food they consume, while families in rural areas purchase only $30 \%$ [12].

Other factors that contribute to the changes in dietary patterns seen in developing countries have been described. A study conducted in South Africa reported some of the factors as increased numbers of women in the workforce with less time to prepare meals for the family, long commuting distances with substantial amount of time spent commuting to and from work, smaller living spaces which are often not equipped with kitchens or outdoor cooking spaces and decreased access to natural fuel sources [13]. All of these factors influence how food is accessed in the urban context. In this study, we assessed the cultural acceptability including perceptions towards, and barriers to, consumption of unrefined carbohydrates (brown rice, unrefined maize, and unrefined sorghum ugali) versus refined grains (white rice and refined maize ugali) in Tanzania. We also evaluated factors which may promote acceptance of unrefined carbohydrates.

\section{Subjects and Methods}

This pilot study was conducted in two regions of Tanzania, Dar es Salaam and Morogoro. Dar es Salaam is the most populous region in Tanzania, and is among the fastest growing cities in Africa [14]. This region was selected because of its high prevalence of nutritional-related chronic diseases. Morogoro region which is located approximately $190 \mathrm{~km}$ west of Dar es Salaam was selected because it is the country's center for agriculture. The main crops grown in Morogoro include cereals (rice, maize, wheat, sorghum, finger millet, and bulrush millet), legumes (beans, cowpeas, pigeon peas, green grams, and peas), tubers (cassava, sweet potatoes, yams, and taro), and many fruits and vegetables.

A total of 45 men and women employed at Muhimbili University of Health and Allied Sciences (MUHAS) in Dar es Salaam $(n=23)$ and Sokoine University of Agriculture (SUA) in Morogoro $(n=22)$ were recruited into the study. Posters were displayed on notice boards for six weeks to recruit potential subjects to participate in the study. The inclusion criteria for this study were (1) age between 40 and 65 years, (2) body mass index (BMI) of $\geq 25 \mathrm{~kg} / \mathrm{m}^{2}$, and (3) habitual consumer of rice and ugali. One participant from Morogoro was excluded because of young age, thus 44 participated in focus group discussions.

The study was approved by the Tanzania National Institute for Medical Research Ethical Review Body and an informed consent was obtained from all participants prior to conducting the study. The breakdown of participants enrolled detailing the regional and gender distribution is shown in Figure 1.

Participants completed a self-administered questionnaire on sociodemographic information (age, sex, marital status, family size, level of education, and years of schooling) and dietary habits, including their preferred carbohydrate staple foods. Socioeconomic status was also determined using a self-administered questionnaire. Participants were then served with an ad libitum meal of the test food (brown rice, unrefined maize ugali, and unrefined sorghum ugali) for lunch which was then followed with focus group discussions (FGDs). A total of twelve FGDs were conducted, six in Dar es Salaam and the other six in Morogoro. Focus groups were held separately for men and women to account for genderrelated perceptions and barriers and also provide an opportunity for women to freely express themselves. To ensure a similar interview technique for the two sites, all the FGDs were moderated by one experienced social scientist from the University of Dar es Salaam, using a FGD guide which was developed to ensure that issues were discussed consistently across groups. A similar instrument was used in parallel studies conducted by our colleagues in Shanghai, China, and Chennai, India with specific cultural modifications [15]. FGDs about brown rice, unrefined maize, and unrefined sorghum ugali were conducted on three consecutive days. Table 1 bellow shows a sample of questions that were used by the FGD moderator during FGD on brown rice. Similar questions were modified for use during FGDs on unrefined maize and unrefined sorghum ugali.

All the FGDs were conducted in Kiswahili (the national language) and audio-recorded using a digital recorder (Olympus VN-7000 Digital Voice Recorder 142645). All audio recordings were then transcribed verbatim and translated into English. Great caution was taken during translation to ensure that no data was lost in the process. Data analysis was conducted using QRS N6 software (QRS International Pty. 


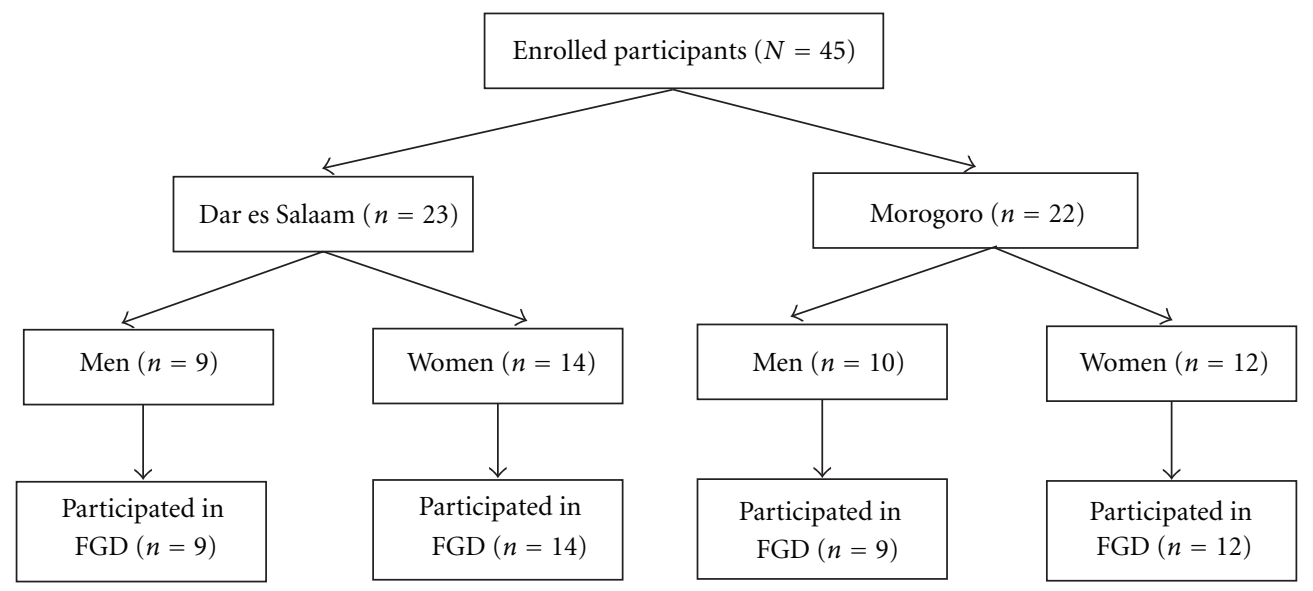

FIGURE 1: Breakdown of participants' enrollment by region and gender.

TABLE 1: Sample questions that were used to guide the focus group discussions.

\begin{tabular}{ll}
\hline & Question \\
(1) & Please describe the kind of foods, including types of rice, that people in your community generally like to eat and why? \\
(2) What are some of the qualities you would look for when you buy rice? \\
(3) What do people generally prefer, white or brown rice, and why is this is so? \\
(4) Earlier on you have all tasted the brown rice, let me know how do you find the taste? Is it palatable? If not, why? \\
(5) Do you think people in general will readily accept brown rice as their staple rice? \\
(6) What are some of the major barriers people experience to consume brown rice? \\
(7) $\quad$ minerals, vitamins, and fiber that white rice does not have? \\
(8) What suggestions do you have to make brown rice more appealing to people?
\end{tabular}

Ltd., Melbourne, Australia, 2002). The text data was entered into the QRS N6 software and systematically analyzed to identify recurrent themes, both within and across gender and regions. The social scientist (E. Shemaghembe) and two other researchers (A. J. Muhihi and M. A. Njelekela) read all the transcripts independently and coded the text data based on the developed themes, and they were organized into three main categories: (1) perceptions about consumption of whole grain foods, (2) factors that may promote consumption of whole grain foods, and (3) barriers that impede consumption of whole grain foods. At the end, they all convened to discuss the themes and patterns to ensure consensus and consistency. All participants provided consent for the discussions that were audio-recorded.

\section{Results}

3.1. Sociodemographic Characteristics of the Study Population. Characteristics of the study population are presented in Table 2. The mean age and BMI of participants were $48 \pm 5$ years and $32 \pm 4.7 \mathrm{~kg} / \mathrm{m}^{2}$, respectively. Gender differences were observed for education (level of education as well as years of schooling), with fewer women having attained advanced education compared to men. In addition, the mean BMI for women was higher compared to that of men. Regional differences were observed for the level of education, with more participants from Morogoro having attained advanced education compared to their counterparts in Dar es Salaam (data not shown).

3.2. Consumption of Unrefined Carbohydrate Staple Foods. All participants except one had tried unrefined maize ugali before. More than three-quarters of the participants $(n=33)$ reported that they liked it. During the focus groups, consumption of unrefined maize ugali was mentioned,

"Unrefined maize ugali is my natural and favorite food and I prefer it more than rice" (Female, Morogoro).

"Unrefined maize ugali is delicious and you can even it [sic] without a relish" (Female, Morogoro).

Unrefined sorghum ugali was less commonly used than unrefined maize ugali. Less than one-third of the participants ( $n=12$ ) reported having tried unrefined sorghum ugali before, and nine of them reported that they liked it. Overall, there were gender differences regarding opinions of sorghum ugali in this study, with some liking it and others raising concerns about its color,

"Yes it is true of what you say. For instance today we have eaten and found it very nice. Other people 
TABLE 2: Sociodemographic characteristics of the study population.

\begin{tabular}{|c|c|c|c|c|c|c|}
\hline & \multicolumn{2}{|c|}{$\operatorname{Men}(N=18)$} & \multicolumn{2}{|c|}{ Women $(N=26)$} & \multicolumn{2}{|c|}{ All $(N=44)$} \\
\hline & Mean \pm SD & $n(\%)$ & Mean \pm SD & $n(\%)$ & Mean \pm SD & $n(\%)$ \\
\hline Age (years) & $47 \pm 5$ & & $48 \pm 5$ & & $48 \pm 5$ & \\
\hline Body mass index $\left(\mathrm{Kg} / \mathrm{m}^{2}\right)^{\dagger}$ & $30.3 \pm 4.7$ & & $32.9 \pm 4.6$ & & $31.9 \pm 4.7$ & \\
\hline \multicolumn{7}{|l|}{ Married } \\
\hline Yes & & $16(88.9)$ & & $17(65.4)$ & & $33(75.0)$ \\
\hline No & & $2(11.1)$ & & $9(34.6)$ & & $11(25.0)$ \\
\hline \multicolumn{7}{|l|}{ Education level $^{\dagger \dagger}$} \\
\hline Ordinary sec education & & $6(33.3)$ & & $12(46.2)$ & & $18(40.9)$ \\
\hline Vocational education & & $4(22.2)$ & & $13(50.0)$ & & $17(38.6)$ \\
\hline Advanced sec education & & $2(11.1)$ & & $0(0.0)$ & & $2(4.6)$ \\
\hline College and/or university & & $6(33.3)$ & & $1(3.8)$ & & $7(15.9)$ \\
\hline \multicolumn{7}{|l|}{ Years of education (years) ${ }^{t \dagger}$} \\
\hline $6-12$ & & $9(50)$ & & $22(84.6)$ & & $31(70.4)$ \\
\hline More than 12 & & $9(50)$ & & $4(15.4)$ & & $13(29.6)$ \\
\hline \multicolumn{7}{|l|}{ Family size } \\
\hline Total number of people & & $6.8 \pm 2.3$ & & $6.8 \pm 2.3$ & & $6.8 \pm 2.3$ \\
\hline Number of adults ( $\geq 18 \mathrm{yrs}$ ) & & $4.1 \pm 1.8$ & & $4.1 \pm 1.8$ & & $4.1 \pm 1.8$ \\
\hline Number of children ( $<18 \mathrm{yrs})$ & & $2.7 \pm 1.6$ & & $2.7 \pm 1.6$ & & $2.7 \pm 1.6$ \\
\hline
\end{tabular}

${ }^{\dagger}$ Statistically significant at 0.05 level.

${ }^{\dagger \dagger}$ Statistically significant at 0.01 level.

lost interest because of its color but when one consumes he/she might need to eat it always" (Female, Morogoro).

"For me, it has good taste because it's not my first time to eat sorghum ugali. In fact, it has reminded me about the past where it used to be my favorite food" (Male, Morogoro).

In focus groups with female participants, the issue of the unappealing color was also mentioned,

"I think it is the color that has made men to lose appetite. Even for us when we saw its color, we took a little portion, but when we started eating, it was so delicious that some of us even went to add more" (Female, Morogoro).

"Today was my first time to taste sorghum ugali. I was initially disappointed when I saw its color, but when I ate it, I liked it more than unrefined maize ugali" (Female, Morogoro).

Brown rice was relatively unknown to the majority of participants both in Dar es Salaam and Morogoro. Only four people reported that they had tried brown rice before (Morogoro $(n=3)$ and Dar es Salaam $(n=1))$, but they all liked it. Despite the fact that this was the first time for most participants to try brown rice, they seemed to like it,

"Although it is my first time to taste brown rice, I find it just delicious" (Male, Dar es Salaam).

"As for me, I like it, if I get used to it, I will be eating it" (Female, Morogoro).
3.3. Perceptions about Consumption of Unrefined Carbohydrate Foods. Consumption of unrefined carbohydrate foods is linked to the socioeconomic status of the family; those consuming unrefined carbohydrate foods are perceived as being poor and those consuming refined carbohydrate as wealthy,

"When you eat unrefined maize ugali here in town, you are regarded as a poor person, but when I go to the village I eat unrefined maize ugali comfortably because it is a normal food in the village" (Female, Dar es Salaam).

"I think another reason is the negative perception that a person who consumes unrefined ugali is seen as poor, and the one who consumes refined ugali is seen as rich" (Male, Morogoro).

Sorghum is considered to be a nutritious food and is used to make porridge for children as well as during the fasting Muslim holy month of "Ramadhani." Despite its high nutritional value, there were some misconceptions due to its additional use in some regions for making local brew.

"Many people use sorghum for making alcohol. It is also used for making porridge during the Muslim fasting month of Ramadhani" (Female, Morogoro).

"Here in Dar es Salaam, sorghum is demanded very much as a nutritious food. It's just people's perspectives that's why they said it is used for making local brew" (Male, Dar es Salaam).

Most people who had heard about brown rice had a belief that it is a therapeutic diet for diabetic patients, 
"I have heard about brown rice before, but it is a food for patients with diabetes. They are the ones who are told by doctor to eat brown rice" (Male, Dar es Salaam).

"I have heard of brown rice before but I had never tasted it. All I knew was that, it is for people with diabetes. Then why should I bother to taste while I am not sick?" (Female, Dar es Salaam).

3.4. Factors That Determine Food Choice. Accessibility, affordability, taste, and color emerged as the most important factors that people consider when purchasing food,

\begin{abstract}
"It is not possible to get unrefined maize flour in a local shop, therefore we just buy the refined maize flour." It is because they are easily accessible and cheap. Refine carbohydrate foods are easily available around our communities" (Female, Morogoro).

"As for me I usually consider the color. I like the white sorghum with small grains" (Male, Morogoro).
\end{abstract}

For rice, it was clear that participants also preferred rice cultivated from certain geographical areas in Tanzania,

\begin{abstract}
"I prefer rice from Kyela. Firstly, because they preserve it in good conditions, they do not dry it on the ground, rather they use tents. So it usually does not have stones. Secondly it's because it smells real good that it makes you want to eat even if you are full" (A male participant, Dar es Salaam).
\end{abstract}

Other factors such as traditions and customs were also pointed out as determinants of food choice. Some participants reported consuming foods which were more popular and culturally acceptable in their tribes. Interestingly, most participants stated that the need to eat or fill their stomachs was more important than nutritional content, when it comes to selecting foods,

"Oh! You think we eat certain foods because of their nutritional content? No, we eat what is available at that particular time. Most of us need just to fill our stomachs to enable us to see the next day" (Male, Morogoro).

3.5. Barriers to Consumption of Unrefined Carbohydrate Foods. High cost and unavailability of brown rice were strong barriers to its consumption. Brown rice is found only in supermarkets where people of higher socioeconomic status go to shop and is also sold at a higher price than white rice. This is not the case for sorghum flour which is easily available in local markets and shops,

"The problem with brown rice is that it is sold at higher price and it is not available in our normal shops. It can only be found in the supermarkets and shopping malls" (Female, Dar es Salaam).
Contrary to Dar es Salaam, the price for brown rice in Morogoro was comparable to that of white rice. The main barrier to its consumption in this region was lack of knowledge about the possible health benefits of brown rice,

"I think people do not understand the health benefits of brown rice. It is not about price but preference because some other local white rice brands are sold at higher price than that of brown rice" (Male, Morogoro).

Long waiting times for milling unrefined maize were mentioned as a barrier to consumption of unrefined maize ugali. Milling of unrefined grains is usually done at the end of the work day so as not to distort the white color of refined grains. Waiting to the end of the day for milling discourages many people from using unrefined maize flour,

"The problem is that the owners of the milling machines make those who come for milling unrefined maize wait to the end. This discourages people and they ask themselves, why should they waste their time waiting while there is white and refined maize flour?" (Male, Dar es Salaam).

Moving to urban settings was mentioned to be a reason for changes in dietary habits that are currently underway in Tanzania. Occupation also plays a great deal in influencing what people eat. Because most of the times they are at work, they do not have time to prepare food for themselves. As a result, they sometimes prefer to eat foods that are easy to prepare or take away such as French fries with chicken or with fried eggs,

"We used to eat unrefined maize ugali, but since we moved to the city, our habits and attitudes to food have changed" (Female, Dar es Salaam).

"Most of the times we are at work and we cannot go home to prepare food. What we eat at lunch is French fries with a soft drink or water or some snacks which are easily available" (Female, Morogoro).

"Sometimes you get back home from work while very tired, so you just find something easy to prepare like French fries or sausage" (Female, Dar es Salaam).

\section{Discussion}

This study provides evidence that unrefined maize ugali was generally preferred as a substitute for refined carbohydrates in Tanzania compared to unrefined sorghum ugali and brown rice. Additionally, unrefined maize ugali and unrefined sorghum ugali are well-known staple foods, and that their consumption is generally acceptable in both regions. Brown rice, however, is unfamiliar to the majority of Tanzanians and its consumption is low. Few people who had knowledge about brown rice either had a friend or a relative who was diabetic. 
This study has uncovered several factors that influence food choices in Tanzania. Availability, affordability, and sensory attributes (color and taste) were found to influence people's choice and consequently purchase and consumption of foods. These findings are consistent with reports from other studies [16], which have also shown that availability, sensory appeal, and cost are important factors that affect people's food choices. Unlike in developed countries where health concerns play a key role in food choice $[17,18]$, this is not yet the case in most developing countries. As revealed in this study, knowledge about the nutritional content of food is low among Tanzanians, thus health concerns and nutritional content play a minimal role in choosing foods.

Consumption of unrefined carbohydrates in Tanzania faces several negative perceptions. People who consume unrefined maize ugali in urban areas are generally regarded as having low socioeconomic status. White rice and refined maize ugali are currently the most popular staple foods in urban settings. Health education is therefore important in order to change people's perception and promote consumption of unrefined carbohydrates.

Several barriers to the consumption of whole grain foods exist. While the availability of brown rice is limited both in urban and rural settings, the supply of unrefined maize and sorghum flour is abundant in rural settings but limited in urban areas. In Dar es Salaam, brown rice is available only in supermarkets and shopping malls and is sold at a higher price. Availability has been reported in other studies as a barrier to consumption of certain foods [16]. High cost of brown rice in Dar es Salaam is a strong barrier to its consumption. Its price is almost twice that of white rice. Other studies have also reported high cost of whole grain foods to be a barrier to their consumption [17]. Unrefined maize and sorghum flour are relatively cheap and widely available in rural settings [10].

Tanzania has the potential to produce enough food for local consumption, but because of lack of national strategies to encourage consumption of healthy and locally produced foods, there is high consumption of imported carbohydrates and other processed foods in urban areas [19]. As a consequence, Tanzania is facing a rising burden of diet-related chronic diseases including T2DM $[20,21]$. The prevalence of T2DM was $0.5 \%$ among rural inhabitants and $1.9 \%$ among urban dwellers three decades ago [22]. Survey data indicate that the burden of T2DM in Tanzania has increased sixfold between 1989 and $2000[20,21]$, with approximately 380,000 people living with T2DM in 2003. More recent estimates show that approximately half a million people have T2DM in Tanzania and that this number is expected to double by 2030 [23]. Further studies are needed to explore the relationship between nutrition transition and the current prevalence of T2DM in Tanzania.

Whole grain foods deliver a unique nutrient package rich in vitamins and minerals, unsaturated fatty acids, tocopherols, tocotrienols, fibers, stanols, sphingolipids, resistant starch, and antioxidants like phenolic acid [24]. Consumption of whole grain foods has been shown to be associated with a $26 \%$ reduction in heart disease [25], a 21 to 43 percent reduction in the risk of cancer [26] and more than a $20 \%$ reduction in the risk of T2DM $[27,28]$. From the focus group discussions, it was shown that people like these whole grain staples and may be aware of their nutritive value to certain extent; however, their use is increasingly limited. Some participants, especially men, were hesitant about the color of unrefined sorghum ugali, but upon consumption, they liked it. With the above-mentioned health benefits of whole grains in reducing the risk of cancer, heart diseases, and T2DM, it is evident that if consumption of unrefined carbohydrates is widely advocated, it can help to reduce the rising burden of diet-related chronic diseases in Tanzania.

In conclusion, the findings of this study highlight a number of barriers that should be addressed through nutritional educational programs in order to promote wider consumption of unrefined carbohydrates in Tanzania. The study provides a platform for the introduction of strategies to combat diet-related chronic diseases in Tanzania. Provision of education on the health benefits of unrefined carbohydrates and pursuing policies that encourage consumption and research on whole grains in Tanzania should be a priority. Availability and cost of unrefined carbohydrates is not a problem in rural settings. Theses staples should be made widely available in urban areas as well.

\section{Acknowledgments}

The authors are very grateful to all the participants who agreed to take part in this pilot study. They thank Muhimbili National Hospital $(\mathrm{MNH})$ and Sokoine University of Agriculture (SUA) for providing venues where focus group discussions were conducted. The paper received funding from the Department of Nutrition, Harvard School of Public Health.

\section{References}

[1] T. N. Maletnlema, "A Tanzanian perspective on the nutrition transition and its implications for health," Public Health Nutrition, vol. 5, no. 1 A, pp. 163-168, 2002.

[2] B. M. Popkin, "The nutrition transition and obesity in the developing world," Journal of Nutrition, vol. 131, no. 3, pp. 871S-873S, 2001.

[3] A. Astrup, J. Dyerberg, M. Selleck, and S. Stender, "Nutrition transition and its relationship to the development of obesity and related chronic diseases," Obesity Reviews, vol. 9, supplement 1, pp. 48-52, 2008.

[4] M. C. Mazengo, O. Simell, Z. Lukmanji, R. Shirima, and R. L. Karvetti, "Food consumption in 1 ural and urban Tanzania," Acta Tropica, vol. 68, no. 3, pp. 313-326, 1997.

[5] M. Njelekela, K. Ikeda, J. Mtabaji, and Y. Yamori, "Dietary habits, plasma polyunsaturated fatty acids and selected coronary disease risk factors in Tanzania," East African Medical Journal, vol. 82, no. 11, pp. 572-578, 2005.

[6] WHO, "Obesity: preventing and managing the global epidemic," Report of a WHO Consultation, Technical Report Series, World Health Organization, 2000.

[7] K. Weinberger and I. Swai, "Consumption of traditional vegetables in Central and Northeastern Tanzania," Ecology of Food and Nutrition, vol. 45, no. 2, pp. 87-103, 2006.

[8] T. S. Msuya, J. R. Kideghesh, and E. J. Luoga, "Consumption of indigineous fruits in uluguru north and ruve north forest 
reserves," Tanzania. Journal of Forestry and Nature Conservation, vol. 75, pp. 65-73, 2004.

[9] M. Njelekela, T. Sato, Y. Nara et al., "Nutritional variation and cardiovascular risk factors in Tanzania-Rural-urban difference," South African Medical Journal, vol. 93, no. 4, pp. 295-299, 2003.

[10] FAO, Nutrition Country Profile, United Republic of Tanzania, 2008.

[11] K. Susan, B. Emmanuel, and D. Dimitri, "Urban agriculture in low income households of harare: an adaptive response to economic crisis," Journal of Human Ecology, vol. 32, no. 2, pp. 85-96, 2010.

[12] J. Garrett and M. Ruel, Food Security in the Context of Urban Sub-Saharan Africa: FoodAfrica, Internet Forum, 1999.

[13] T. Annemarie, B. Priscilla, and C. Boonzaaier, "Factors contributing to changes in food practices of a black South african community," Journal of Family Ecology and Consumer Sciences, vol. 33, 2005.

[14] "The world's fastest growing cities and urban areas from 2006 to 2020: City Mayors Statistics," http://www.citymayors.com/ statistics/urban_growth1.html.

[15] G. Zhang, V. S. Malik, A. Pan et al., "Substituting brown rice for white rice to lower diabetes risk: a Focus-Group Study in Chinese Adults," Journal of the American Dietetic Association, vol. 110, no. 8, pp. 1216-1221, 2010.

[16] J. Pollard, S. F. L. Kirk, and J. E. Cade, "Factors affecting food choice in relation to fruit and vegetable intake: a review," Nutrition Research Reviews, vol. 15, no. 2, pp. 373-387, 2002.

[17] E. M. M. McMackin and M. Dean, "Barriers and the facilitators of whole grain consumption in Northern Ireland," Proceedings of the Nutrition Society, vol. 69(OCE5), p. E349, 2010.

[18] M. Ree, N. Riediger, and M. H. Moghadasian, "Factors affecting food selection in Canadian population," European Journal of Clinical Nutrition, vol. 62, no. 11, pp. 1255-1262, 2008.

[19] FAO, Tanzania nutrition profile, 2008.

[20] T. J. Aspray, F. Mugusi, S. Rashid et al., "Rural and urban differences in diabetes prevalence in Tanzania: the role of obesity, physical inactivity and urban living," Transactions of the Royal Society of Tropical Medicine and Hygiene, vol. 94, no. 6, pp. 637-644, 2000.

[21] D. G. McLarty, A. B. M. Swai, H. M. Kitange et al., "Prevalence of diabetes and impaired glucose tolerance in rural Tanzania," Lancet, vol. 1, no. 8643, pp. 871-875, 1989.

[22] B. Ahren and C. B. Corrigan, "Prevalence of diabetes mellitus in North-Western Tanzania," Diabetologia, vol. 26, no. 5, pp. 333-336, 1984.

[23] J. E. Shaw, R. A. Sicree, and P. Z. Zimmet, "Global estimates of the prevalence of diabetes for 2010 and 2030," Diabetes Research and Clinical Practice, vol. 87, no. 1, pp. 4-14, 2010.

[24] H. E. Miller, F. Rigelhof, L. Marquart, A. Prakash, and M. Kanter, "Antioxidant content of whole grain breakfast cereals, fruits and vegetables," Journal of the American College of Nutrition, vol. 19, supplement 3, pp. 312S-319S, 2000.

[25] J. W. Anderson, T. J. Hanna, X. Peng, and R. J. Kryscio, "Whole grain foods and heart disease risk," Journal of the American College of Nutrition, vol. 19, supplement 3, pp. 291S-299S, 2000.

[26] D. R. Jacobs, L. Marquart, J. Slavin, and L. H. Kushi, "Wholegrain intake and cancer: an expanded review and metaanalysis," Nutrition and Cancer, vol. 30, no. 2, pp. 85-96, 1998.
[27] S. Liu, J. E. Manson, M. J. Stamfer et al., "A prospective study of whole-grain intake and risk of type 2 diabetes mellitus in US women," American Journal of Public Health, vol. 90, no. 9, pp. 1409-1415, 2000.

[28] K. A. Meyer, L. H. Kushi, D. R. Jacobs, J. Slavin, T. A. Sellers, and A. R. Folsom, "Carbohydrates, dietary fiber, and incident type 2 diabetes in older women," American Journal of Clinical Nutrition, vol. 71, no. 4, pp. 921-930, 2000. 


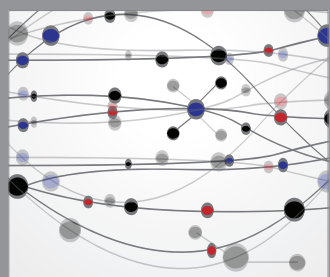

The Scientific World Journal
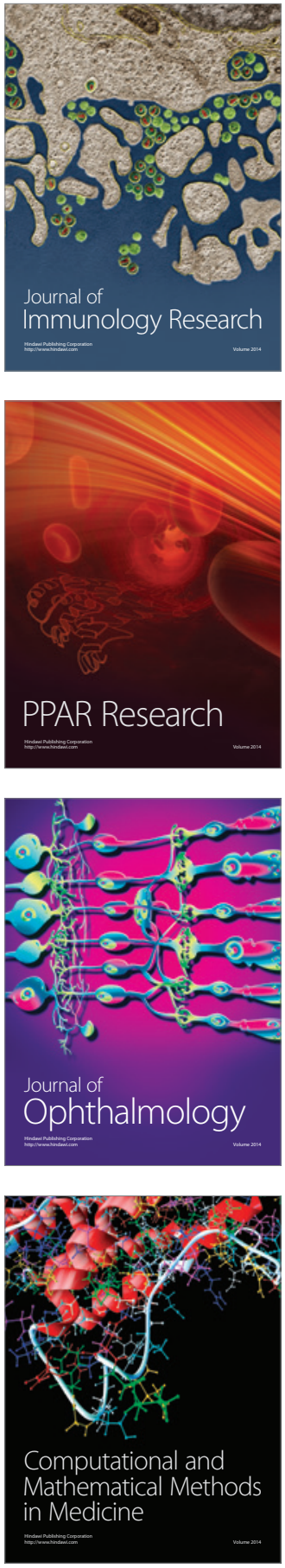

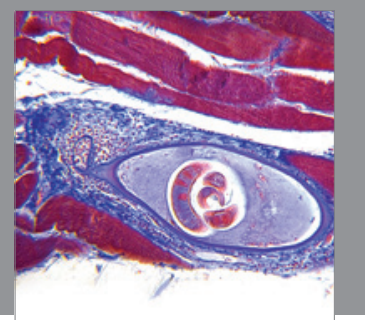

Gastroenterology

Research and Practice
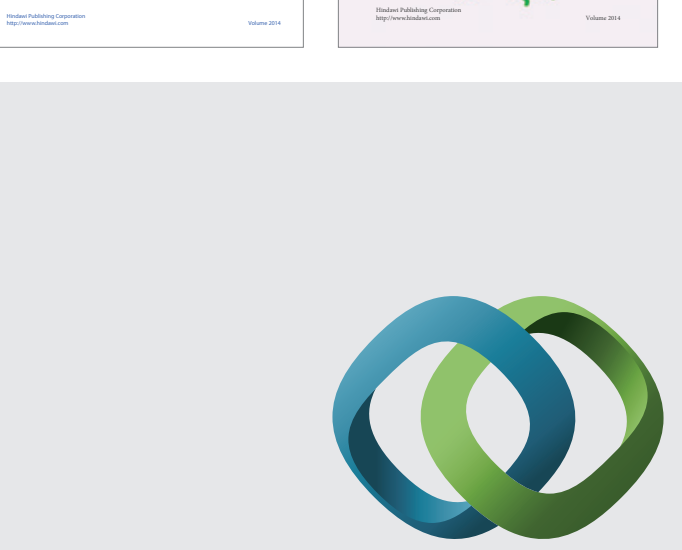

\section{Hindawi}

Submit your manuscripts at

http://www.hindawi.com
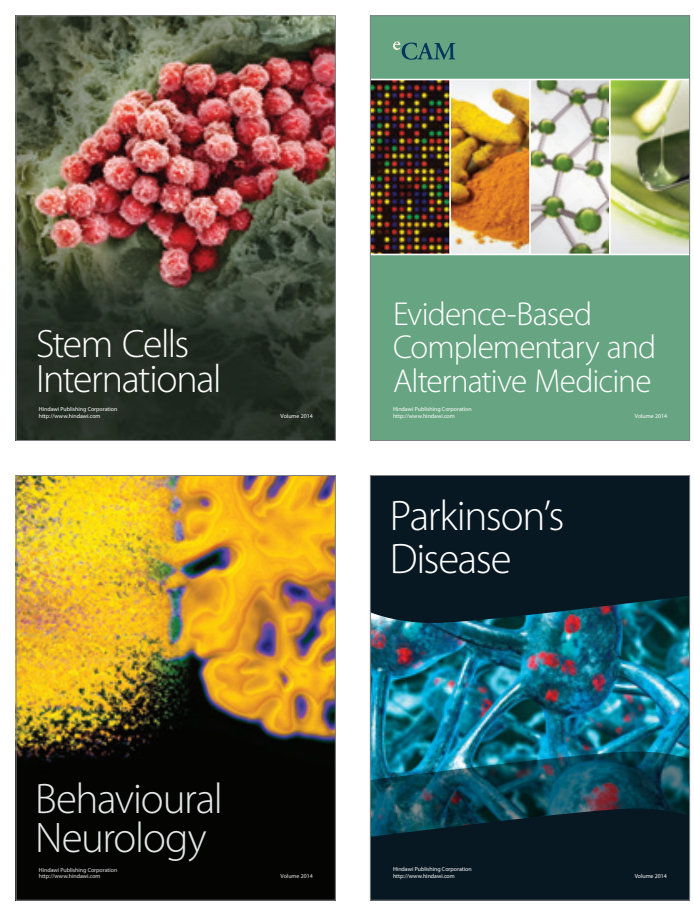

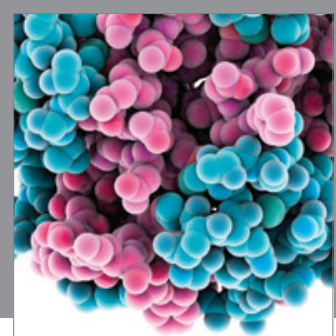

Journal of
Diabetes Research

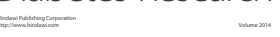

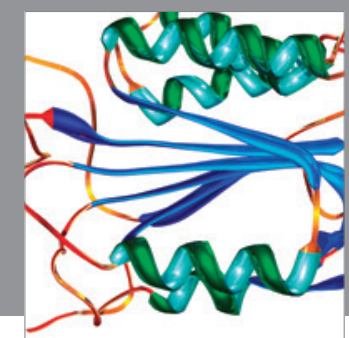

Disease Markers
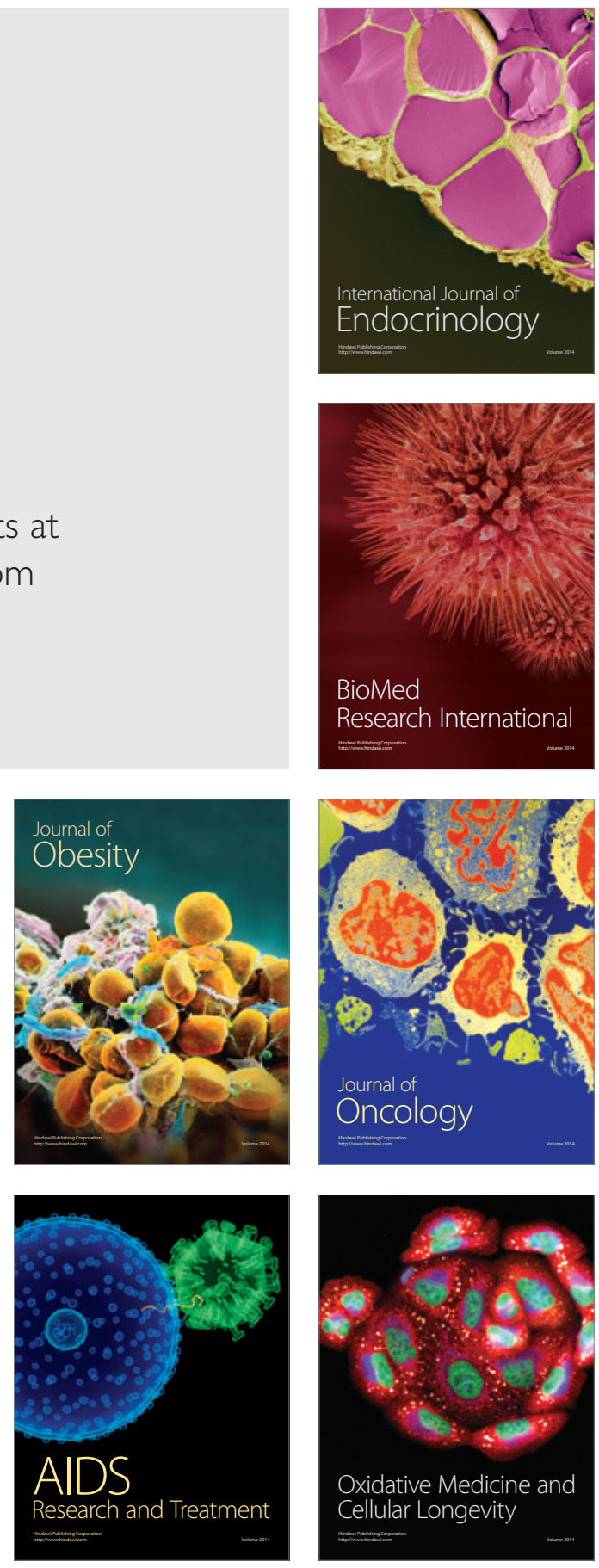